Thorax (1967), 22, 88.

\title{
The dynamics of cough in health and in chronic bronchitis
}

\author{
J E A N L A N G L A N D S \\ From the Department of Therapeutics and Pharmacology, Queen's University, Belfast
}

The bronchi and the intrathoracic trachea are compressed and narrowed during coughing or forced expiration. In normal people the narrowing is evenly distributed ; in patients who have airflow obstruction it is greater and more irregular and sometimes causes almost complete obliteration of the main bronchi (Di Rienzo, 1949; Gandevia, 1963). The narrowing results from a transmural pressure gradient between the extraluminal pressure, which is fairly evenly distributed along the airways, and the intraluminal pressure, which falls from the alveoli to the mouth. This gradient, and therefore the narrowing tendency, is greatest in the trachea and large bronchi. The small bronchi are thin-walled and depend on the radial support of the surrounding lung parenchyma to maintain their patency. The medium-sized and large bronchi are partly protected by the thickness of their walls and the presence of cartilaginous plates, but even the large bronchi and trachea can be distorted by invagination of the membranous parts between their plates. If emphysema is present the broken-down lung parenchyma gives less radial support to the airways during expiration, and the walls of the bronchi may be atrophic and more readily distorted (Wright, 1960). Any obstruction in the small airways reduces the 'downstream' intraluminal pressure during expiration, and this increases the transmural pressure gradient and the tendency of the large airways to narrow during expiration (Campbell, Martin, and Riley, 1957).

Much has been written about the effect of airway compression on gas flow during forced expiration, notably by Fry and Hyatt (1960), who studied transpulmonary pressure/lung volume/ flow relationships by means of three-dimensional models. Less attention has been paid to the effect of airway compression on gas flow during coughing. Whittenberger and Mead (1952) recorded oesophageal pressure and simultaneous gas flow at the mouth during coughing in three normal and two emphysematous subjects. They found lower flow rates despite high pressures, and higher transpulmonary resistances in the emphysematous subjects. Ross, Gramiak, and Rahn (1955) recorded oesophageal pressure, tracheal diameter, and gas flow at the mouth during coughing in a normal subject, and estimated that there was a high linear speed of gas flow in the compressed trachea. Dayman (1961) noted notching or fluttering in records of flow during coughing, especially in patients who had air flow obstruction. He ascribed this to compression and rebound of the airways.

In the present study, transpulmonary pressure, gas flow at the mouth, and expired volumes were recorded during coughing and during forced expiration in 10 patients with chronic bronchitis and in 10 normal subjects who had been paired with the bronchitics according to age and physical characteristics. Records from five younger normal subjects have also been studied.

\section{SUBJECTS, APPARATUS, AND PROCEDURES}

The diagnostic criteria used by Elmes, Fletcher, and Dutton (1957) were used to select 10 patients with chronic bronchitis. All had had a productive winter cough for at least three years and had suffered two or more exacerbations with increased cough and sputum during this period. They were investigated between exacerbations. The presence of gross pulmonary pathology, other than chronic bronchitis and emphysema, was excluded by chest radiographs. Each bronchitic patient was matched in sex and, as closely as possible, in age and standing height with a control subject chosen from patients who had been under our care for non-pulmonary medical conditions or under orthopaedic care for limb fractures. The controls had no history of pulmonary disease and had normal chest radiographs. The physical characteristics of the controls and bronchitics are shown in Table I. Six of the bronchitics smoked more than 70 cigarettes a week, four of the six more than 140 a week. Seven of the controls smoked more than 70 cigarettes a week, one of the seven more than 140 a week. The five younger normal subjects were medically qualified, and none of them smoked. 
T A B LE I

MATCHING OF BRONCHITICS AND CONTROLS

\begin{tabular}{|c|c|c|c|c|c|c|c|}
\hline \multirow{2}{*}{$\begin{array}{l}\text { No. of } \\
\text { Pair }\end{array}$} & \multirow[b]{2}{*}{ Sex } & \multicolumn{3}{|c|}{ Bronchitics } & \multicolumn{3}{|c|}{ Controls } \\
\hline & & Age (yrs) & $\underset{\text { in. }}{\mathrm{He}}$ & $\begin{array}{l}\text { ight } \\
\mathrm{cm} .\end{array}$ & Age (yrs) & $\underset{\text { in. }}{\mathbf{H}}$ & $\begin{array}{l}\text { ight } \\
\mathrm{cm} \text {. }\end{array}$ \\
\hline \multirow[t]{2}{*}{$\begin{array}{r}1 \\
2 \\
3 \\
4 \\
5 \\
6 \\
7 \\
8 \\
9 \\
10\end{array}$} & $\begin{array}{l}\mathbf{M} \\
\mathbf{M} \\
\mathbf{M} \\
\mathbf{M} \\
\mathbf{M} \\
\mathbf{M} \\
\mathbf{M} \\
\mathbf{M} \\
\mathbf{F} \\
\mathbf{F}\end{array}$ & $\begin{array}{l}39 \\
46 \\
49 \\
51 \\
60 \\
51 \\
58 \\
56 \\
47 \\
49\end{array}$ & $\begin{array}{l}69 \\
68 \\
68 \\
70 \\
65 \\
67 \\
65 \\
66 \\
58 \\
63\end{array}$ & $\begin{array}{l}175 \\
172 \\
172 \\
177 \\
165 \\
170 \\
165 \\
167 \\
147 \\
160\end{array}$ & $\begin{array}{l}40 \\
46 \\
49 \\
52 \\
57 \\
52 \\
53 \\
56 \\
47 \\
45\end{array}$ & $\begin{array}{l}68 \\
69 \\
71 \\
69 \\
67 \\
67 \\
65 \\
66 \\
61 \\
63\end{array}$ & $\begin{array}{l}172 \\
175 \\
180 \\
175 \\
170 \\
170 \\
165 \\
167 \\
154 \\
160\end{array}$ \\
\hline & Mean & 51 & 66 & 167 & 50 & 67 & 170 \\
\hline
\end{tabular}

Transpulmonary pressure was measured as the difference between the oesophageal pressure and pressure at the mouth (Fry, Stead, Ebert, Lubin, and Wells, 1952). One chamber of a differential inductive manometer was connected by polyethylene tubing to an air-filled oesophageal balloon which was about $15 \mathrm{~cm}$. long and $3 \mathrm{ml}$. in capacity. The other chamber was connected to a side opening in the mouthpiece of the pneumotachograph. The balloon was swallowed until it lay in the lower part of the oesophagus, and it was filled with 2 to $2.5 \mathrm{ml}$. of air. Gas flow at the mouth was recorded by a Lilly (1950) type pneumotachograph which was tested with constant flow rates of up to $3751 . / \mathrm{min}$. and responded linearly. The response times of the pressure and flow recording systems were less than 0.05 second. Volume changes were measured by electronic integration of flow. Inspiration and expiration were integrated separately, the capacitator being automatically discharged by a relay at flow reversal so that integration started afresh at zero at each change of phase of flow. Pressure, flow, and volume were recorded simultaneously by a direct writing recorder.

Three forced vital capacities (F.V.C.) were recorded from each subject. The subject was then asked to inspire fully and to cough as hard as possible through the pneumotachograph. Three bouts of voluntary coughing were recorded, each with at least four successive coughs interrupted by inspirations. Coughing was also excited reflexly by inhalation of an aerosol of $30 \%$ citric acid from a hand nebulizer. The nozzle of the nebulizer fitted into an oblique hole in the side wall of the pneumotachograph mouthpiece without projecting into its lumen. The bulb of the nebulizer was squeezed while the subject inspired deeply. This induced cough in about $80 \%$ of subjects at the first attempt, but tolerance developed and it was not always possible to induce cough on three occasions.

\section{MEASUREMENTS}

DURING VOLUNTARY COUGHING A record of a bout of voluntary coughing in a control subject is shown in
Figure 1. In each of the first four coughs of the bout, the maximum transpulmonary pressure (c), the peak flow rate (P.F.R.) (b), and the volume of expired gas (f) were measured from the record. The highest transpulmonary pressure reached during the bout was also measured. Each parameter was measured from records of three bouts of coughing for each subject and the mean was taken.

At the time of maximum transpulmonary pressure, the flow had usually fallen from its peak rate to a level (e) which was maintained relatively constant for an instant. This level, which is hereafter called the plateau flow rate, was present in all records of cough from controls and bronchitics. In records of cough from young normal subjects it was not always present in the first voluntary cough, although it was seen in later coughs at lower lung volumes (Fig. 2). From one record of a bout of voluntary coughing from each bronchitic and control, in each of the first four coughs of the bout, measurements were made of the plateau flow rate and the volume (d) expired from total lung capacity at the time of maximum pressure. The maximum transpulmonary resistance of the first four coughs was calculated by dividing the maximum transpulmonary pressure by the plateau flow rate (c/e). No attempt was made to estimate and subtract the elastic component of transpulmonary pressure from the total transpulmonary pressure before calculating resistance, but Whittenberger and Mead (1952) have pointed out that the elastic pressure is small compared with the flow-resistive pressure during coughing.

DURING FORCED EXPIRATION The maximum transpulmonary pressure and the P.F.R., F.V.C., and F.E.V.1.0 were measured from records of three forced expirations for each subject, and the mean was taken (Comroe, Forster, DuBois, Briscoe, and Carlsen, 1962).

DURING INDUCED COUGHING It was found that flow and volume were very variable in any subject because they depended on the depth of the previous inspiration, which was determined by the point at which sufficient aerosol had been inhaled to induce coughing. Only the maximum transpulmonary pressure reached during the bout was measured from the records, and the mean was taken if more than one record was available for each subject.

\section{RESULTS}

PATTERN OF PRESSURE AND FLOW DURING VOLUNTARY COUGHING Examples of records taken from normal and bronchitic subjects are shown in Figures 1 and 2 . In all subjects at the beginning of the first cough the glottis closed and the transpulmonary pressure began to rise in a compressive phase. The time of closure of the glottis was usually marked by a small expiratory deflection 


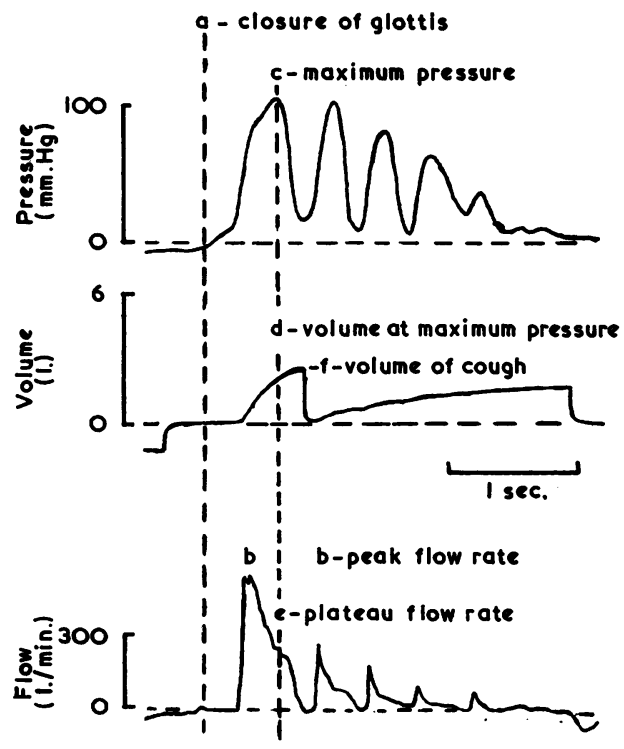

FIG. 1. Record of a bout of five successive voluntary coughs from a control subject. (a) Time of closure of glottis and start of compressive phase; (b) peak flow rate; (c) maximum pressure; (d) volume expired from total lung capacity at maximum pressure; (e) plateau flow rate at maximum pressure; $(f)$ volume of first cough. The volume tracing was sometimes electronically returned to zero at no flow as at the end of the first cough, and sometimes not returned to zero as at the end of subsequent coughs.
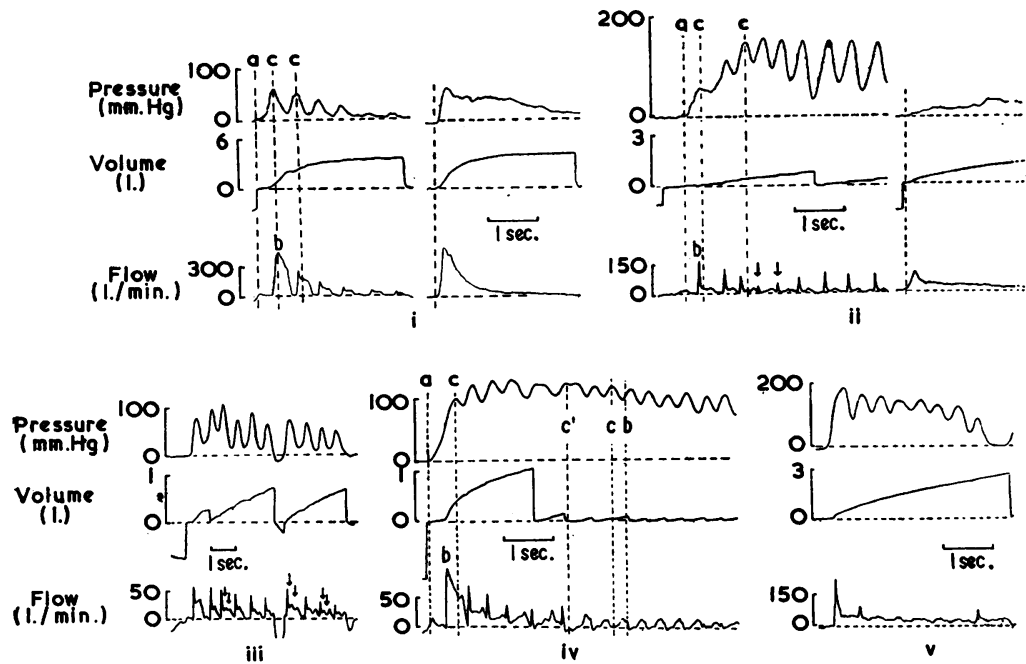

FIG. 2. (i) Record of a bout of voluntary coughs and a forced expiration from a young normal subject. In this subject the peak flow rate of the first cough occurs at the time of maximum pressure. (ii) Record of a bout of voluntary coughs and part of a forced expiration from a bronchitic subject. Despite persistently high pressures during coughing the flow rates achieved are low, in fact the higher the pressures the lower the peak flow rates (arrowed). (iii), (iv), and (v) Other records of bouts of voluntary coughs from bronchitic subjects to show the following abnormalities of the flow tracings: (iii) repetitive notching (arrowed); (iv) from ( $\left.c^{\prime}\right)$ onwards there is no flow at the maximum pressure of coughs; (v) flow continues during the compressive phase of coughs. (a), (b), and (c) as in Fig. 1. 
of the flow tracing. There was no further flow for about $0.2 \mathrm{sec}$., until the transpulmonary pressure increased considerably, when the glottis opened and a peak rate of flow was rapidly attained. The transpulmonary pressure continued to rise after the glottis had opened.

In three young normal subjects the P.F.R. occurred at maximum transpulmonary pressure in the first cough (Fig. 2 (i)). In two young normal subjects, the 10 controls, and one bronchitic, the P.F.R. preceded the maximum transpulmonary pressure, and the flow tracing fell in a smooth curve to a gradually downward sloping plateau at the time of maximum transpulmonary pressure (Fig. 1). The pressure decreased fairly rapidly after its maximum but did not fall to zero; the flow fell to zero after the glottis had closed, the pressure mounted, and the cycle was repeated in the second cough. In subsequent coughs the flow tracing was angulated before the plateau. The peak flow rate and volume were much larger in the first cough and became progressively smaller in subsequent coughs.

In nine out of 10 bronchitics the flow tracing of the first cough showed an early, ill-sustained peak and fell abruptly to an angle or notch followed by a low plateau at the time of maximum pressure (Fig. 2 (ii)). The peak flow rates and volumes of successive coughs remained relatively constant in bronchitics but high transpulmonary pressures were sometimes associated with unusually low peak flow rates. The notching was sometimes repetitive (Fig. 2 (iii)). In two bronchitics, after the first few coughs of a bout of coughing, the flow ceased at the maximum pressure of each cough ( $c^{\prime}$ in Fig. 2) and gas was expelled only when the pressure fell at the end of each cough (Fig. 2 (iv)). The transpulmonary pressure tended to remain higher between coughs in the bronchitics than in the controls and sometimes the flow did not cease completely between coughs (Fig. 2 (v)).

A bronchitic patient was asked to give short bouts of coughs with varying force, starting each bout after full inspiration (Fig. 3). As the maximum transpulmonary pressure of the first cough of each bout was increased, there was a marked decrease in the plateau flow rate and volume and a slight decrease in the peak flow rate.

MAXIMUM TRANSPULMONARY PRESSURE (Table II) During voluntary coughing the mean maximum

T A B L E I I

SUMMARY OF RESULTS

\begin{tabular}{|c|c|c|c|c|c|}
\hline & \multicolumn{2}{|c|}{10 Bronchitics } & \multicolumn{2}{|c|}{10 Controls } & \multirow{2}{*}{$\begin{array}{l}5 \text { Young } \\
\text { Normals } \\
\text { Mean }\end{array}$} \\
\hline & Mean & S.D. & Mean & S.D. & \\
\hline $\begin{array}{l}\text { Forced expiration } \\
\text { F.E.V. } \\
\text { F.V.C.(1.) } \\
\text { P.F.R.(1.) } \\
\text { Maximum pres- }\end{array}$ & $\begin{array}{r}1 \cdot 4 \\
3 \cdot 3 \\
155\end{array}$ & $\begin{array}{l}0.7 \\
1.4 \\
73\end{array}$ & $\begin{array}{r}3 \cdot 3 \\
5 \cdot 1 \\
359\end{array}$ & $\begin{array}{r}0.7 \\
0.8 \\
122\end{array}$ & $\begin{array}{r}4 \cdot 2 \\
5 \cdot 4 \\
558\end{array}$ \\
\hline $\begin{array}{l}\text { sure (mm.Hg) } \\
\text { Voluntary cough } \\
\text { Volume of first }\end{array}$ & 57 & 32 & 38 & 24 & 60 \\
\hline $\begin{array}{l}\text { cough (1.) } \\
\text { P.F.R. of first }\end{array}$ & 0.5 & 0.2 & 1.7 & 0.7 & $2 \cdot 3$ \\
\hline $\begin{array}{l}\text { cough (1./min.) } \\
\text { Maximum pres- }\end{array}$ & 165 & 70 & 487 & 138 & 514 \\
\hline $\begin{array}{l}\text { sure (mm.Hg) } \\
\text { Induced cough } \\
\text { Maximum pres- }\end{array}$ & 167 & 36 & 117 & 31 & 77 \\
\hline sure $(\mathrm{mm} . \mathrm{Hg})$ & $\begin{array}{l}180 \\
\text { (of } 8)\end{array}$ & - & $\begin{array}{l}147 \\
\text { (of } 8)\end{array}$ & 一 & $\begin{array}{l}118 \\
\text { (of } 4)\end{array}$ \\
\hline
\end{tabular}

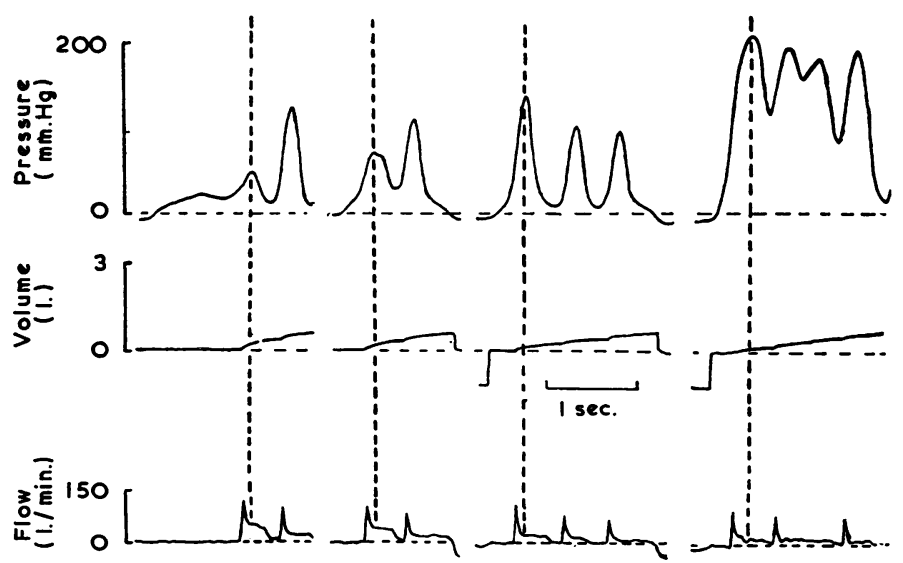

FIG. 3. Effect of voluntary alterations in pressure on the flow rate and volume of the first cough after full inspiration in a bronchitic patient. The dashed lines show the time relationship of the maximum transpulmonary pressure of the first cough to the flow tracing. 
transpulmonary pressure was $77 \mathrm{~mm} . \mathrm{Hg}$ in the young normal subjects, $117 \mathrm{~mm} . \mathbf{H g}$ in the controls, and $167 \mathrm{~mm}$. $\mathrm{Hg}$ in the bronchitics; the difference in pressure between the controls and bronchitics was highly significant $(0.01>P>$ 0.001 ). During forced expiration the mean maximum transpulmonary pressure was $60 \mathrm{~mm}$. $\mathrm{Hg}$ in the young normal subjects, $38 \mathrm{~mm}$. $\mathrm{Hg}$ in the controls, and $57 \mathrm{~mm}$. $\mathrm{Hg}$ in the bronchitics; the difference in pressure between the controls and the bronchitics was not statistically significant. During induced coughing the mean maximum transpulmonary pressure in the young normal subjects, controls, and bronchitics respectively was 118 , 147, and $180 \mathrm{~mm}$. $\mathrm{Hg}$.

VOLUME AND PEAK FLOW RATE (Table II) A bout of coughing resembles a series of short forced expirations, so that the duration of a cough is one of the factors affecting the volume expired during the cough. The mean duration of the first voluntary sough was $0.50 \mathrm{sec}$. in the controls and 0.49 sec. in the bronchitics. The volume of the first voluntary cough in the controls and bronchitics has been plotted against the F.E.V..$_{1 \cdot 0}$ in Figure 4. The correlation was highly significant $(r=0.83)$.

In the controls, the mean P.F.R. was $4871 . / \mathrm{min}$. in the first voluntary cough and $3591 . / \mathrm{min}$. in a forced expiration. The difference was highly significant $(0.01>P>0.001)$. In the bronchitics the mean P.F.R. was $165 \mathrm{l} . / \mathrm{min}$. in the first voluntary

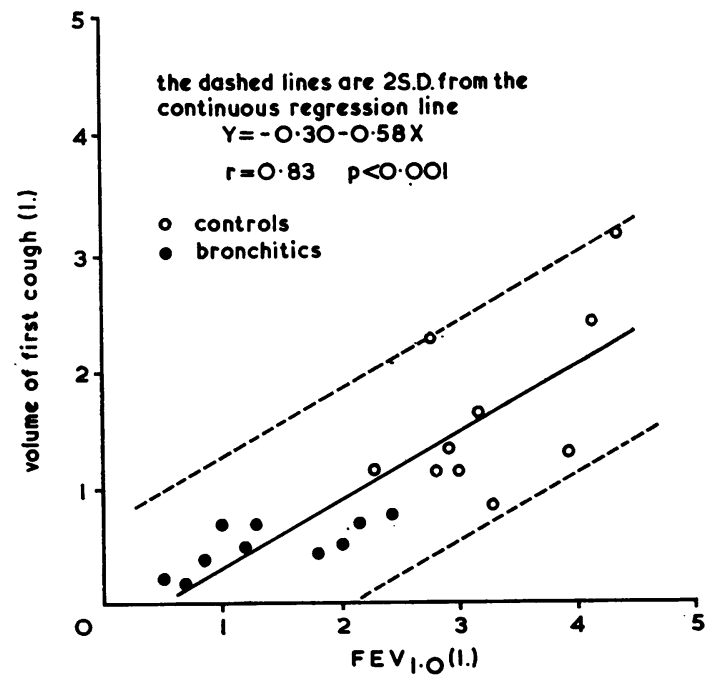

FIG. 4. Regression of the volume of the first voluntary cough on the F.E.V.1.0 in a pooled group of 10 control and 10 bronchitic subjects. cough, which differed little from the mean P.F.R. of $155 \mathrm{l} . / \mathrm{min}$. in a forced expiration.

PARAMETERS OF SUCCESSIVE COUGHS The maxi- $\frac{\bar{m}}{\frac{D}{2}}$ mum transpulmonary pressure of a bout of $\stackrel{\mathbb{Q}}{\mathscr{Q}}$ voluntary coughing occurred in the first three or four coughs. After this the maximum pressure of $\vec{\circ}$ successive coughs decreased with the reduction in lung volume (Fig. 5). The mean P.F.R. and the $\vec{\omega}$

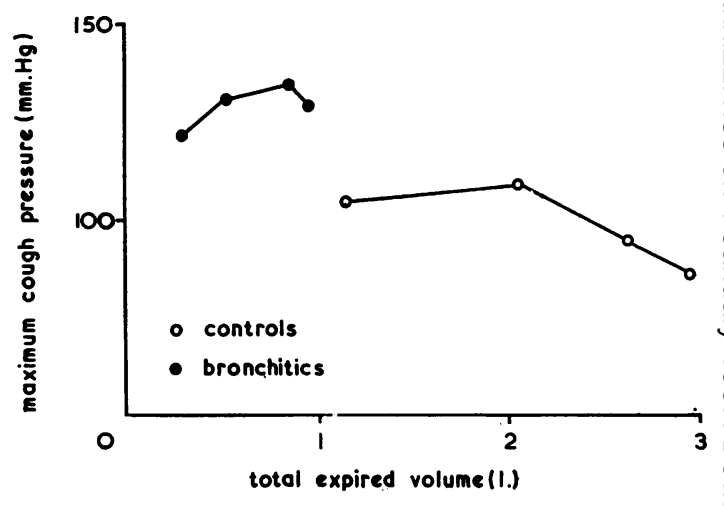

FIG. 5. Mean maximum transpulmonary pressure of each of the first four coughs of a bout of voluntary cough- 요 ing, plotted against the mean volume expired from total $\stackrel{\odot}{\circ}$ lung capacity, in controls and bronchitics.

mean plateau flow rate of the first four successive coughs decreased proportionately to the reduction in lung volume (Fig. 6). The maximum transpulmonary resistance of the first four coughs in each control and bronchitic subject has been $\underset{x}{2}$ plotted against the volume expired from total lung $\dot{\sigma}$ capacity in Figure 7. In two subjects the record is incomplete because of a leak in the oesophageal 0 balloon. With one exception the maximum transpulmonary resistance was higher in the bron- o chitics than in the controls and increased more steeply in successive coughs.

\section{DISCUSSION}

RELATIONSHIP BETWEEN COUGH AND FORCED N EXPIRATION A bout of coughing resembles a series of short forced expirations at decreasing 6

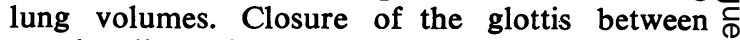
coughs allows the pressure in the alveoli and air- $\stackrel{\mathcal{D}}{?}$ ways to equilibrate, and the airways to regain 0 their normal size for the lung volume before the $\bar{O}$ next cough. In a forced expiration, Fry and Hyatt $\stackrel{\mathbb{D}}{\stackrel{D}{ }}$ (1960) describe an initial phase in which the flow $\mathbb{\mathbb { D }}$ increases with effort to a maximum or peak flow, $\frac{\Omega}{\sigma}$ and a later phase in which a further increase in 
pressure causes a decrease in flow or 'pressureflow dissociation' due to narrowing of the airway and peripheral air trapping. The maximum flow in the initial phase may depend on the rate at which the pressure is developed, at least at high lung volumes. In the later phase the flow remains relatively constant for a given lung volume over a wide range of pressures. Gandevia (1963) describes an angle or notch in the forced expiratory spirograms of some patients with emphysema. $\mathrm{He}$ ascribes this to a sudden collapse of the airway walls at the beginning of the phase of pressureflow dissociation.

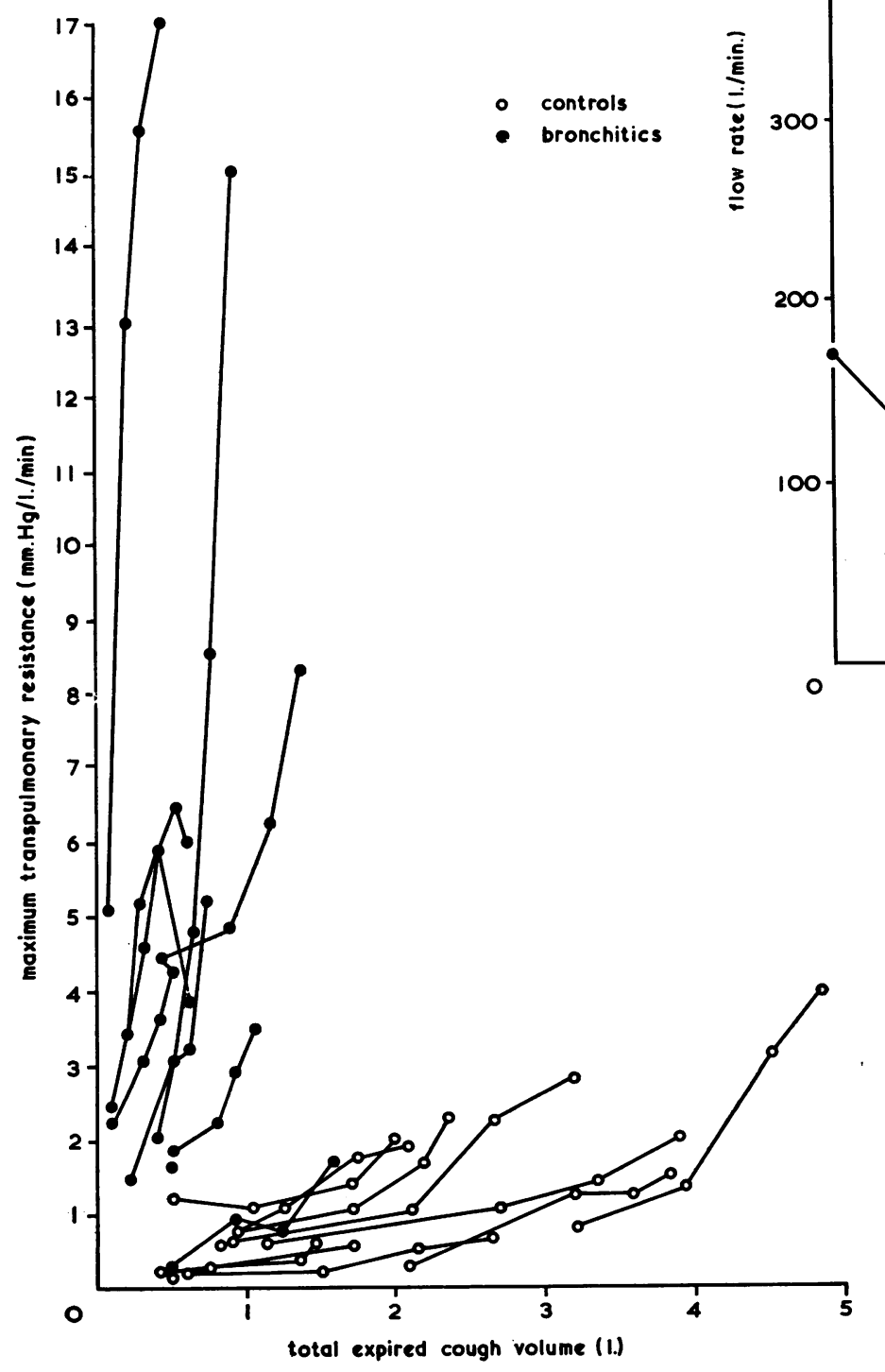

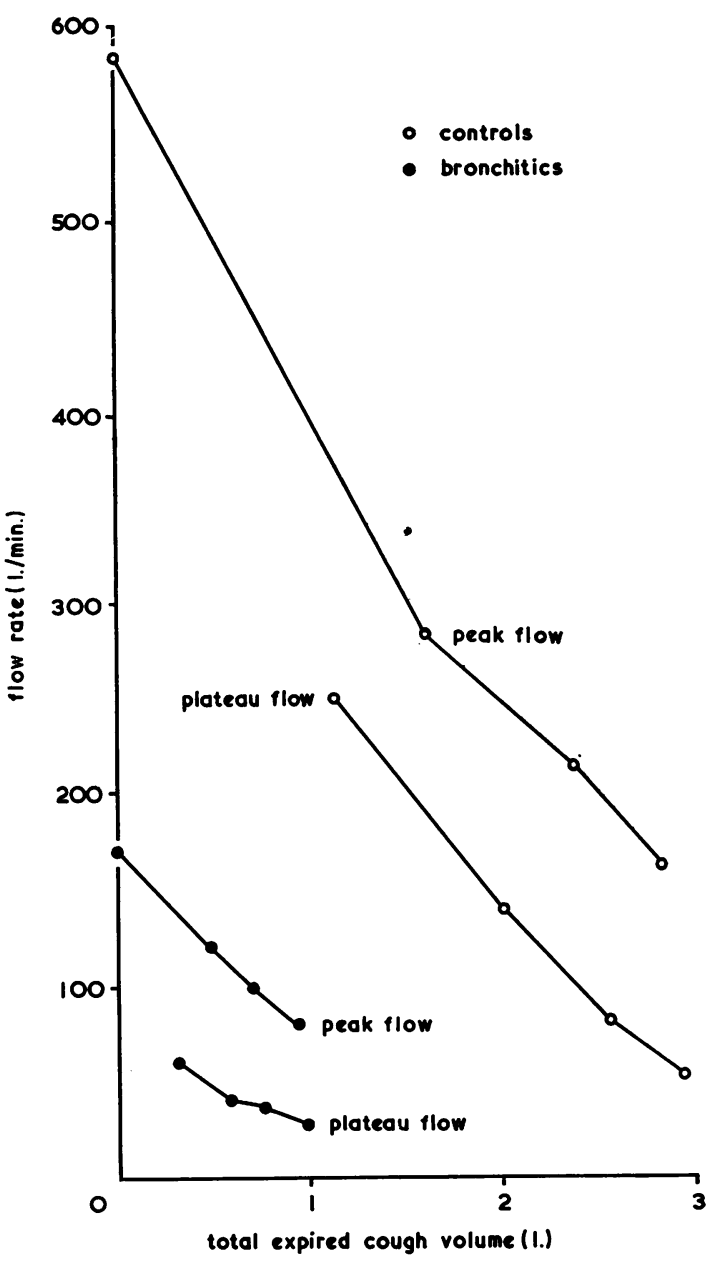

FIG. 6. Mean peak flow rate and mean platean flow rate of each of the first four coughs of a bout of voluntary coughing, plotted against the mean volume expired from total lung capacity, in controls and bronchitics.

FIG. 7. Maximum transpulmonary resistance of each of the first four successive voluntary coughs, plotted against the volume expired from total lung capacity, in controls and bronchitics. 
In a cough the pressure builds up behind the closed glottis before flow starts, whereas in expiration the pressure rise and flow start simultaneously. The higher initial pressure at the start of the expiratory phase of cough results in a more rapid increase to a peak rate of flow in cough than in forced expiration. The maximum pressure during coughing was also higher than the maximum pressure during forced expiration in most controls and bronchitics (Table II). The difference in pressure resulted, in the controls, in a significantly higher P.F.R. during the first voluntary cough than during forced expiration. A greater difference in pressure in the bronchitics did not result in a significant difference between the P.F.R. of the first cough and the P.F.R. of forced expiration, probably because of an onset of pressure-flow dissociation at higher lung volumes in the bronchitics than in the controls. In nine bronchitics there was an angle or notch due to airway collapse in flow tracings of the first voluntary cough, but in only four of these was there an angle in the flow tracings of forced expiration, because of the higher pressure during coughing than during forced expiration. The angle was not seen in flow tracings of the first cough or of forced expiration in the normal subjects.

\section{DYNAMICS OF COUGH}

In Normal Subjects At the beginning of a cough the glottis closes, the expiratory muscles contract, and pleural pressure starts to rise. Muscular contraction continues to raise the pressure after the glottis opens, gas is forced out, and the flow increases rapidly to a peak rate. In young normal subjects, coughing at a high lung volume, the peak expiratory flow may occur at the time of maximum pressure. In young normal subjects coughing at lower lung volumes, and in older normal subjects, compressive airway narrowing causes pressure-flow dissociation before maximum pressure is reached. When further narrowing of the airways is limited by the resistance to deformation of the airway walls, the flow tracing levels out in a plateau with a gradual downward slope. Then the expiratory muscles relax, the pressure falls, although not to atmospheric pressure, the glottis closes, and flow stops. In the next cough the initial lung volume and airway diameter are less, and there is a smaller fall in lung volume before the resistance to deformation of the airway wall limits flow. There is an earlier onset of the plateau of the flow tracing, and the peak flow rate and plateau flow rate are reduced proportionately to the reduction in lung volume. The differences which are found between records of cough in controls and young normal subjects are probably due to the effects of ageing, air pollution, and cigarette smoking on the lungs of the controls.

In Bronchitic Subjects The degree of airflow obstruction in the chronic bronchitics varied as judged by the F.E.V.1.0. The following interpretation applies to records from all the bronchitics except one (No. 7), whose airway obstruction was minimal. When the glottis opens in the expulsive phase of a cough, there is a greater transmural pressure drop in the trachea and large bronchi in the bronchitics, because of distal airway obstruction caused by pathological changes in the airways. Sudden collapse of the larger airways ensues which limits the initial rise in flow rate and causes the flow tracing to show an early peak followed by an abrupt fall to an angle or notch and a low plateau flow rate. Notching, sometimes repetitive, is due to over-collapse followed by rebound caused by the resilience of the airway walls.

The high maximum transpulmonary pressure and low plateau flow rate of coughs in bronchitics result in a high maximum transpulmonary resistance which increases steeply in successive coughs (Fig. 7). Two subjects developed transient complete obstruction to flow at the maximum pressure of coughs after the first few coughs of a bout of coughing. In the example illustrated in Fig. 2 (iv) the subject has an F.V.C. of 2.9 litres. She has expired about 1.21 . from total lung capacity in voluntary coughs before flow ceases at the maximum pressure of each cough. The complete airway obstruction may be caused by closure of the glottis in this phase of the cough cycle, due to altered cough mechanics. Examination of the records suggests that it is more likely to be due to closure of the intrathoracic airways, which are severely narrowed at the maximum pressure of the first few coughs and close completely at the maximum pressure of subsequent coughs. The fall of pressure at the end of each cough allows the airways to open and gas to escape in a reversal of the normal pattern of flow in coughs.

CLOSURE OF THE GLOTTIS IN BRONCHITIC SUBJECTS In some subjects the glottis may not close between coughs, so that flow is continuous, or it may close momentarily or incompletely, so that there is not time for the compressed airways to regain their normal size between coughs. The P.F.R. of the 
succeeding cough is then unusually small (Fig. 2 (ii) and (v) ). This was seen only in records from bronchitic subjects and was associated with a high transpulmonary pressure which was sustained with little fall between coughs. Contraction of the adductor muscles of the glottis can be produced by artificial inflation of the lungs, presumably through stimulation of stretch receptors in the walls of the large airways (Green and Neil, 1955). It is possible that stimulation of stretch receptors by the large fluctuations in pressure and volume which normally occur during coughing are necessary for the mechanism of closure of the glottis between coughs. A high and sustained transpulmonary pressure during coughing in bronchitics may result in a continuously low pressure and volume in the subglottic airways, which may interfere with the reflex mechanism of closure of the glottis.

EFFECT OF LUNG VOLUME ON COUGHS The maximum pressure which can be developed by contraction of the muscles of expiration falls as the volume of gas in the lungs diminishes (Rahn, Otis, Chadwick, and Fenn, 1946). Escape of gas from the alveoli and airways during a cough reduces the resistance of the lung to compression and therefore the pleural pressure which can be developed by muscle contraction. Lung volume diminishes more slowly in successive coughs and gas escapes less readily during each cough in bronchitics who have airflow obstruction than in normal subjects, so the transpulmonary pressure tends to remain higher during a bout of coughing in bronchitics (Fig. 5). Other factors which may increase transpulmonary pressure in bronchitics are the progression of a cough which started voluntarily into an uncontrolled involuntary spasm, and possibly the greater practice which bronchitics have in coughing. In the present study the difference in the maximum transpulmonary pressure of a bout of voluntary coughing in the controls and the bronchitics was highly significant. A high pleural and high alveolar pressure tends to squeeze blood out of the pulmonary capillaries and to obstruct pulmonary blood flow. Four of the bronchitics had at some time had cough syncope or dizziness. The flow rates which can be achieved by maximum effort also fall as the lung volume diminishes (Fry and Hyatt, 1960). In consequence the P.F.R. and plateau flow rate of the first few successive coughs fell rapidly in the controls but tended to remain relatively constant in the bronchitics. The fall in mean plateau flow rate per unit fall in lung volume was slightly less in the bronchitics than in the controls (Fig. 6): this was noted by Dayman (1961) to occur both during forced expiration and during successive coughs.

MAXIMUM PRESSURE IN VOLUNTARY AND INDUCED COUGHS The mean maximum transpulmonary pressure was greater during coughing induced by inhalation of citric acid than during voluntary coughing in the young normal, control, and bronchitic groups. The difference was least in the bronchitic group, where the mean maximum pressure of voluntary coughs was highest, and it was not statistically significant in any group.

A high transpulmonary pressure during a bout of coughing may reduce flow rates, especially in patients with obstructive airway disease. Low flow rates maintain the lung volume and therefore the transpulmonary pressure at a high level during the bout. Thus a vicious circle develops, resulting in distress and sometimes dizziness and syncope. Patients who have sputum to expectorate may find that voluntary coughing causes less distress than spontaneous coughing.

EFFICACY OF COUGH Ross et al. (1955) pointed out that airway compression during coughing results in a high linear velocity in the airways. It is the linear velocity which determines the force available for the displacement and acceleration of sputum, so that airway narrowing may be expected to increase the efficacy of cough, at least in normal subjects. The effect of the greater degree of airway narrowing, sometimes amounting to transient complete obstruction, in those who have obstructive disease on the displacement of sputum in the intrathoracic airways is complex and speculative. However, the extrathoracic trachea and upper airways are not compressed, so that in patients with obstructive disease the linear velocity through these airways is very low. This must render the final stages of expectoration difficult in bronchitics, or in any patient whose lower airways are narrowed or obstructed. Where sputum is present, postural drainage is an important part of the treatment of these patients.

\section{SUMMARY}

Ten bronchitic subjects were matched by 10 controls in sex, age, and height. Five younger normal subjects were also studied. Transpulmonary pressure, expired volumes, and gas flow at the mouth were measured during voluntary coughing and forced expiration, and transpul- 
monary pressure was measured during coughing induced by a citric acid inhalation. A bout of continuous coughing resembled a series of short forced expirations at decreasing lung volumes, but differed in that pressure built up behind a closed glottis before each cough, and the maximum transpulmonary pressure was usually much higher during coughing than during forced expiration. Records of cough from the bronchitics showed higher transpulmonary pressures and lower volumes and flow rates than records of coughs from the controls. Some records of coughs from the bronchitics also showed abnormal flow patterns and a failure of the glottis to close between coughs: this was thought to be caused by extreme airway narrowing. In the bronchitics the lung volume did not fall very much in successive coughs, so that the transpulmonary pressure tended to be maintained at a high level during a bout of coughing. The mean maximum transpulmonary pressure was higher during induced coughing than during voluntary coughing in each of the three groups of subjects.

Postural coughing may help bronchitics in two ways. It may prevent distress caused by involuntary bouts of coughing, since voluntary coughing is often less forceful, and it aids expectoration of sputum from the upper airways in patients with low flow rates during coughing.
The author is greatly indebted to Professor O. $\mathrm{L}$ Wade for encouragement, the provision of facilities? and permission to study his patients, and to John $\mathbf{M}$ 음 Collins for technical assistance. This work formed? part of a thesis which was submitted to St. Andrews University for the degree of M.D.

\section{REFERENCES}

Campbell, E. J. M., Martin, H. B., and Riley, R. L. (1957). Mech-二 anisms of airway obstruction. Bull. Johns Hopk. Hosp., 101, $329 \vec{\omega}$

Comroe, J. H., Forster, R. E., DuBois, A. B., Briscoe, W. A., and Carlsen, E. (1962). The Lung, 2nd ed., p. 200. Year Book Publishers, Chicago.

Dayman, H. (1961). The expiratory spirogram. Amer. Rev. resp. Dis. 83,842 .

Elmes, P. C., Fletcher, C. M., and Dutton, A. A. C. (1957). Prophy lactic use of oxytetracycline for exacerbations of chronic bron $\infty$ chitis. Brit. med. J., 2, 1272.

Fry, D. L., and Hyatt, R. E. (1960). Pulmonary mechanics. A unifie analysis of the relationship between pressure, volume and ga $\$$ flow in the lungs of normal and diseased human subjects. Amer J. Med., 29, 672.

- Stead, W. W., Ebert, R. V., Lubin, R. I., and Wells, H. S@̆ (1952). The measurement of intraesophageal pressure and it relationship to intrathoracic pressure. J. Lab. clin. Med., 40, 664

Gandevia, B. (1963). The spirogram of gross expiratory tracheo bronchial collapse in emphysema. Quart. J. Med., N.S. 32, 23.

Green, J. H., and Neil, E. (1955). The respiratory function of the laryngeal muscles. J. Physiol. (Lond.), 129, 134.

Lilly, J. C. (1950). Flow meter for recording respiratory flow of human subjects. Meth. Med. Res., $2,113$.

Rahn, H., Otis, A. B., Chadwick, L. E., and Fenn, W. O. (1946) The pressure-volume diagram of the thorax and lung. Amer. $J$ Physiol., 146, 161.

Di Rienzo, S. (1949). Bronchial dynamism. Radiology, 53, 168.

Ross, B. D., Gramiak, R., and Rahn, H. (1955). Physical dynamic of the cough mechanism. J. appl. Physiol., 8, 264.

Whittenberger, J. L., and Mead, J. (1952). Respiratory dynamic $\$$ during cough. Trans. nat. Ass. Tuberc. (Lond.), 48, 414.

Wright, R. R. (1960). Bronchial atrophy and collapse in chronis obstructive pulmonary emphysema, Amer. J. Path., 37, 63. 